\title{
Zero-fossil-energy powered infrastructure and buildings on Catalina Island in Southern California
}

\author{
T. Spiegelhalter \\ University of Southern California, School of Architecture, USA
}

\begin{abstract}
Buildings, infrastructure, and the landscape in which they are situated are inextricably linked. Energy, materials, water and land are all consumed in the development and operation of buildings and infrastructures on Catalina Island, while the built environment itself affects the live/work conditions, health, ecology and the economy on Catalina Island in Southern California. This research paper presents excerpts of the ongoing $194.19 \mathrm{~km}^{2}$ large infrastructure assessment, and sustainable near-term action plan for the Island of Catalina. It evaluates the typologies of infrastructures and buildings on Catalina Island, and proposes the implementation of energy efficiency retrofitting, off-grid scenarios, and sustainability design strategies for two selected large-scale climate sensitive projects. These two design examples are presented as models for future development that could more serve as a concrete signal of an incentive for successfully protected and enhanced natural environments through ecologically designed buildings for the Santa Catalina Island community. These projects incorporate elements that emphasize the re-emerging role of the landscape as infrastructure and as the basis for passive design strategies that support resource efficient alignment of new buildings on the island.
\end{abstract}

Keywords: sustainability, energy-efficiency retrofitting, zero-fossil-energy development, infrastructure, solar buildings.

\section{Introduction}

Part of the California Channel Islands, Santa Catalina Island is a rocky island off the coast of San Pedro, Los Angeles in Southern California. The island is 22 miles $(35 \mathrm{~km})$ long and 8 miles $(13 \mathrm{~km})$ across at its greatest width. The latitude 
of Santa Catalina is $33.383 \mathrm{~N}$. The longitude is $-118.416 \mathrm{~W}$. The island has an overall population density of $49.29 / \mathrm{mi}^{2}\left(19.03 / \mathrm{km}^{2}\right)$, largely concentrated in the city of Avalon ( 4,500 residents) and the village of Two Harbors ( $\sim 300$ residents). The remaining residents are located at Middle Ranch, Rancho Escondido, Little Harbor, and various camps mostly dotting the leeward shore of the Island.

Over a million tourists visit the island and significantly add to the consumption of resources every year, with approximately 100,000 of them going into the interior of the island on tours that rely on fossil-fuel transportation systems. The leeward shore is the eastern side of the island, which faces the mainland and is sheltered from the prevailing winds. The windward shore is the western side of the island, which faces the outer waters of the Pacific Ocean and the prevailing winds. Most of the island is owned by the Catalina Island Conservancy (a private non-profit organization), which was formed in 1972 to preserve and protect the native plants and animals, biological communities, and geological formations that are of educational or scientific interest. The mission of the Catalina Island Conservancy and many other stakeholders, such as the USC Wrigley Environmental Institute are to be responsible stewards of its lands through a sustainable balance of conservation, education, research, and recreation.

\section{Infrastructure baseline analysis and implementation strategies for upgrades, repair, and renewal}

The Island of Catalina is expected to face some significant issues over the next decade - not the least of which is how to deal with an aging, and increasingly expensive fossil fuel based infrastructure and the effects of pollution which can be attributed to the buildings and transportation systems (Fig. 1).
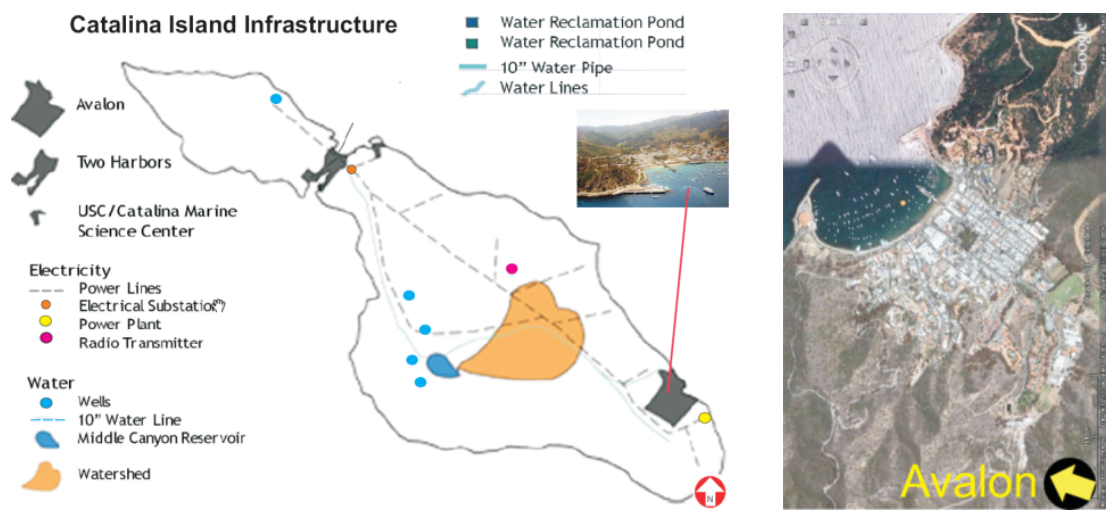

Figure 1: Existing Catalina Island infrastructure diagram analysis: Spring 2007. Th. Spiegelhalter USC-Topic Studio Students. 
Sustainable energy, water, sanitation, and transportation are all key elements for the long-term health and life cycle of the Island, its residents, ecology, culture, and its economy. Each of these critical components of the Island's infrastructure and built environments are going to need upgrades, repair, and renewal over time by adopting conservation strategies, energy efficiency retrofits, and new renewable infrastructures, to significantly minimize resource consumption.

While some of the infrastructure systems are already reaching a critical state, there is still time to act and sustainably plan ahead. In this effort, there is a greater need to consider the long-term consequences of actions and proper investments for the life cycle of systems and resource input and output processes. For example, in 2008, the main Island electricity consumption of 29,749 MWh was related to pumping by $70 \%$, and the rest is related to lighting, heating, refrigeration, transportation, and plug loads. The energy use peaks mostly due to the seasonal tourism from June to September, and in December by $5 \mathrm{MW}$. The residential energy use is higher in January due heating, and the non-residential energy use is highest in July due tourism [1].

Fortunately, the baseline island infrastructure, building analysis and scenario planning is being conducted by the author [2], and the Catalina Island Sustainability Action Group with Dr. Marc Bernstein at a time where there are emerging renewable technologies and building systems that can help the Island become increasingly self-sufficient by 2020 , available to make Catalina Island independent from expensive and unreliable imports of fossil energy. The provided data from Edison [1], on customer energy use, and peak demand was used to analyze, simulate, and conduct assessments for new integrated renewable utility implementation options, low-cost energy-efficiency retrofits, and higher costs solar building systems integrations in exchange for the ability of the island consumers to sell power to the public grid and to obtain carbon offset credits.

\section{Current infrastructural challenges with resource supply, use patterns, and pollution}

Southern California Edison (SCE) provides electricity island-wide, and provides a liquid gas service mainly in the City of Avalon. SCE's diesel powered generators are housed at its facility on Pebbly Beach Road, which is completely separate from SCE's mainland system. The generating station's major equipment systems include six power-generating units with a total capacity of 9.3 megawatts and a maximum dependable output of 6.5 megawatts. The diesel fuel is shipped in by barge from the Port of Los Angeles. Within the city of Avalon, electrical distribution lines are located both overhead and underground; outside the City, most lines are concealed below ridges. In Avalon, electrical distribution facilities are located in alleys and in underground facilities; outside the City, substations are located at Pebbly Beach and Two Harbors. All new developments are required to gain approval from SCE to insure there is an adequate electrical supply for the development, and they must also provide extension of electrical lines where they are not already constructed. Typically, large new developments 
increase the Island's energy demand beyond current supply. In such a cases, SCE invested in additional fossil-energy power generation facilities in the past. Natural gas is shipped to SCE's Pebbly Beach facility on tanker trucks weekly, with shipments based on expected consumption peaks. The SCE storage tank has a capacity to supply about two months of Avalon's demand for gas. The gas is vaporized and distributed by pipeline through the City of Avalon and adjacent areas. SCE has accommodated development and growth in Avalon by extending the gas main pipelines and increasing gas purchases. Most gas main pipeline extensions are financed directly by SCE. The fact that gas is not available outside Avalon means that Two Harbors, the private camps and other inland areas rely on their own fossil-energy storage tanks [3]. The current practice of using diesel to generate electricity and gasoline for transport continues to extract heavy environmental and economic penalties.

\section{Infrastructure assessment and feasibility study for the city of Avalon and two selected building design case studies at two harbors and middle Ranch}

Most of the existing buildings with their connections to the existing infrastructures on Catalina Island need to be substantially renovated, upgraded, or redeveloped to move towards zero-fossil-energy operations. Parallel to the ongoing island-wide infrastructure assessment and implementation strategy development including building energy efficiency retrofit strategies for the City of Avalon, a climate sensitive design research study was conducted for two large-scale building projects on two different sites on Santa Catalina Island. Each of the two sites were analyzed and designed by students of the USC School of Architecture under the leadership of Thomas Spiegelhalter from 2007 to 2008. The directed research and design studio framework was based on multidisciplinary environmental site and systems analysis, design guideline development, and total resource foot printing for future renewable off-grid buildings and infrastructures.

Both projects sites were chosen because of the urgent need for resource efficiency retrofitting redevelopments of existing facilities, and the development of new of additional live/work research facilities for the USC Wrigley Institute and the Santa Catalina Conservancy over the next decades.

One project site for a new all-season Hybrid Campus off-grid design is directly located at the Pacific Ocean on the Island's narrow isthmus on Two Harbors (14-116 feet above sea level). It is located about 10 miles $(16 \mathrm{~km})$ from the only city in the Island, Avalon. Two Harbors is a small island live-work community village located approximately 23 miles $(37 \mathrm{~km})$ from San Pedro Harbor, Long Beach, in Los Angeles.

The other project site is the Santa Catalina Research Conservancy Middle Ranch live-work community located in the mountain interior of Catalina Island at a high altitude (726 feet), and approximately a 1-hour bus drive away on dirt roads from the City of Avalon on Catalina Island. 
Both redevelopment off-grid-design studies were focused on the minimization of energy and water resources for all phases of the life cycle of buildings; considerations were made from their planning to construction through their use, and renovation to their eventual demolition, taking into consideration the reuse and/or recycling of the structural elements.

The scope of the study was to consider component life cycles over 50 to 250 year period, including construction, maintenance, and disassembly. Systems that were researched for this evaluation included highly adaptable and modular longlife structures, passive and active implementation for distributed renewable energy systems (solar, wind, ocean energy, geothermal, biomass), and sustainable transportation systems. In these research studies, passive design strategies were generally prioritized over active systems.

\section{Establishing a design methodology with the customized Catalina ECO-Module Master Planning and Land Use Tool}

In order to tackle the complexity of spatial and performative data to use, analysis, and planning tools were used for the design of the two new projects on Catalina Island. The ECO-Module Master Planning and Land Use Tool for an Integrated Resource Management Design Model was originally developed by the author for other projects in Europe and was specifically customized as an interactive spreadsheet for this Catalina Island Directed Design Research Studio (Fig. 2). Using this tool - an overall set of criteria and framework was developed with maps, graphics, and site-specific weather database for the Two Harbors and Middle Ranch's resource input and output flows in relationship to the ecological footprint of the anticipated new infrastructures and buildings. Evaluations were made as to where how resources are used, as well as where action might be taken to increase future renewable operated infrastructure efficiency, resource savings, natural resource conservation, and opportunities to measure the sustainability of the natural landscape and integrated building typologies over time.

The Catalina ECO-Module Master Planning and Land Use Tool incorporates the ISO 14000, and the UN ecological footprint method [1] as a main analytical and design guideline factor. These methods were considered in forecasting a building's potential resource consumption based on to how much energy is extracted, processed, transported, used, and could be recycled or re-used. It assisted with the categorization of specific land uses and provided estimates for an area's potential for sustainable land use and environmental protection on Two Harbors and the Middle Ranch. This tool can also aid in identifying implementation strategies for climate mitigation measures and environmental building design guidelines. The Ecological Footprint (http://pthbb.org/natural/footprint/) was used to measure how much productive land and water area is required to produce all the resources that are consumed by the Catalina Island population, as well as the resources used to absorb all the waste it generates (using prevailing technology). The feasibility study also employed also building energy simulation software tools such as ECOTECT, Energy 10, Equest, T-SOL, and PV-SOL. 


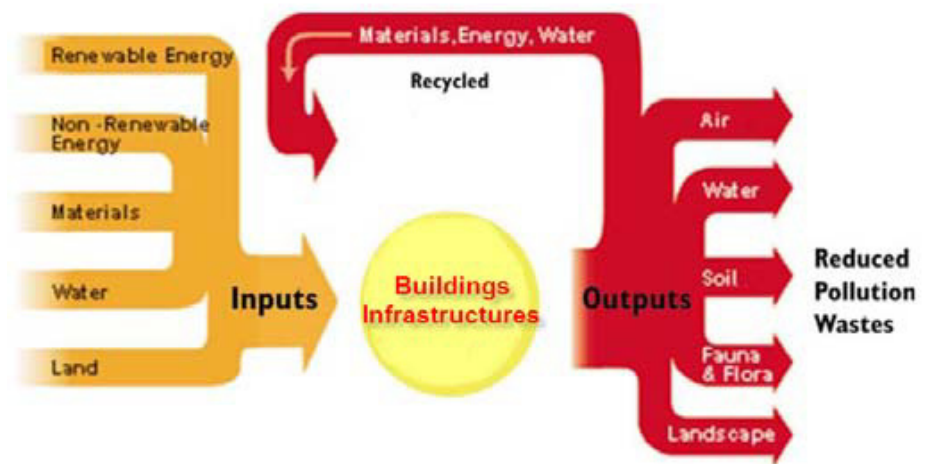

Figure 2: Catalina ECO-Module Master Planning and Land Use Tool for an Integrated Resource Management Design Model (C) Thomas Spiegelhalter.

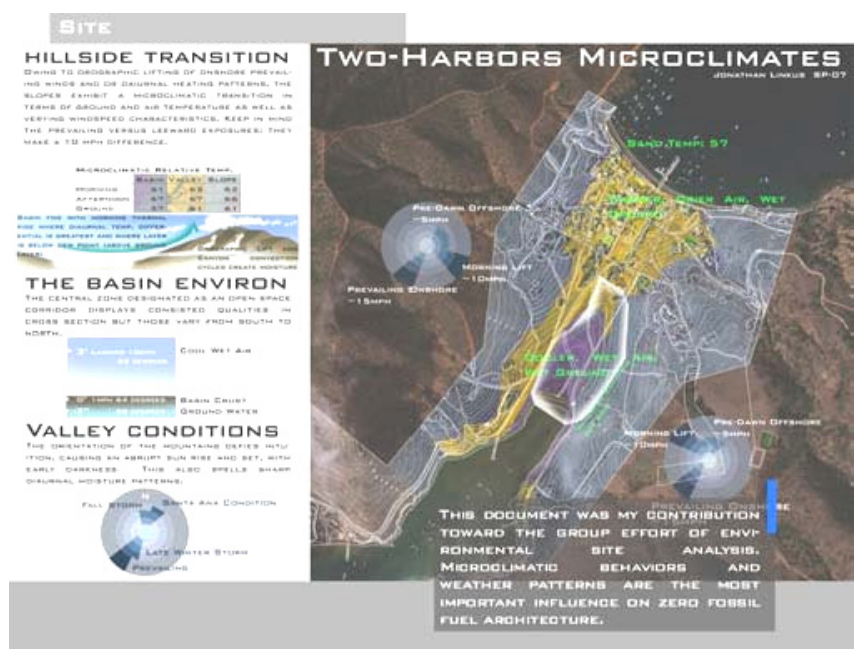

Figure 3: Two harbors micro- and macroclimate analysis for the configuration and sizing of buildings and infrastructures, Analysis: USC-Students: J. Linkus, G. Cao.

\section{Project criteria for the self-sufficient, off-grid mixed-used two harbor campus hybrid buildings}

Two main design research questions drove the analysis: What constitutes largescale off-grid buildings on a remote Island? How will an intimate understanding of natural processes and resources, man-made infrastructure, context, help to determine performance based built form? 


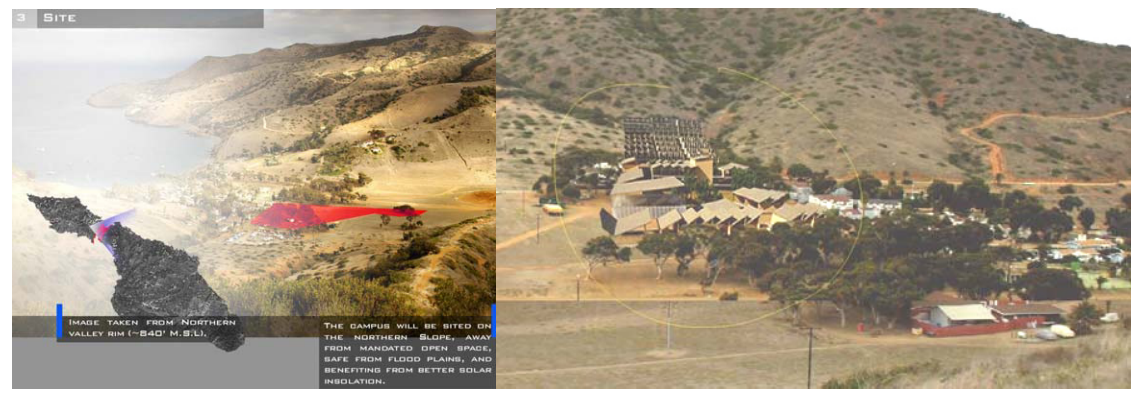

Figure 4: (Left) northeast view of Two Harbors with the Hybrid Campus development area, Students: Jonathan Linkus, Giang Cao. (Right) Development Simulation of the new high-density live-work clusters on Two Harbors, efficiently orientated to the wind and sun patterns, Students: Harout Akopian, Alexander Babich.
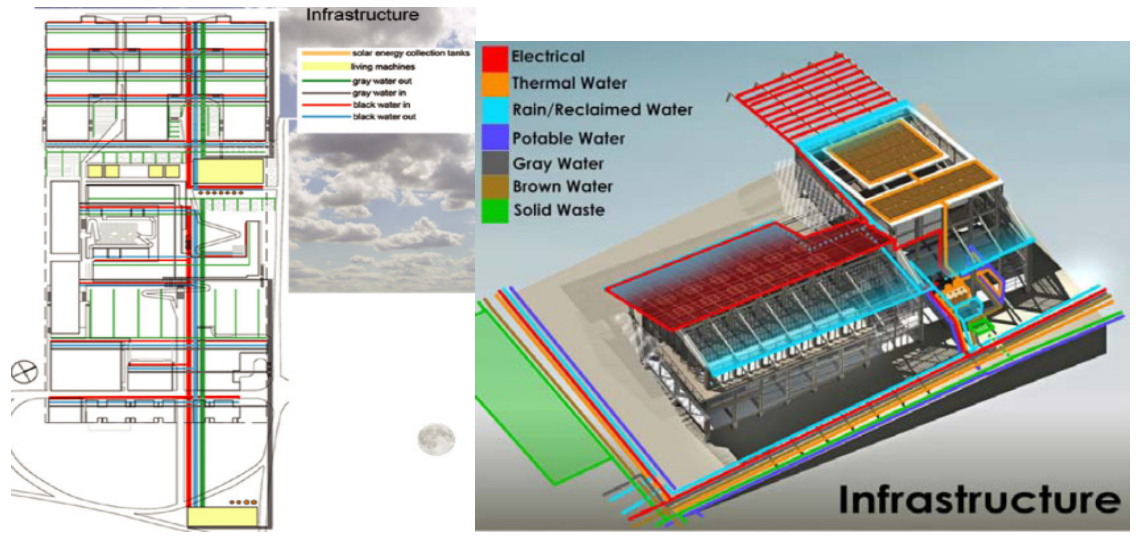

Figure 5: Self-sufficient, renewable energy powered infrastructure proposal for the Hybrid Campus on Two-Harbors, Design: Students: Harout Akopian, Alexander Babich, Jonathan Linkus.

The definition of the word "sustainability" was critically incorporated for the future preservation of three interwoven areas: Climate and ecology, zero-fossil energy infrastructure, buildings, and sustainable practiced economy (Figs. 3 and 5 (left))

The proposed high-density Two-Harbors Hybrid Campus development will be completely self-sustaining with no fossil fuel allowed in any part of the development. The buildings have to be modular, adaptable, flexible, and ecologically sound. The surplus of the energy is sold to the public Catalina Island grid, which acts as storage systems. The total square footage of the project was determined by the analysis of the existing site conditions, flows, circulation, occupancy/program, consumption profile, live/workability, and service/energy systems (Figs. 3 and 4). 


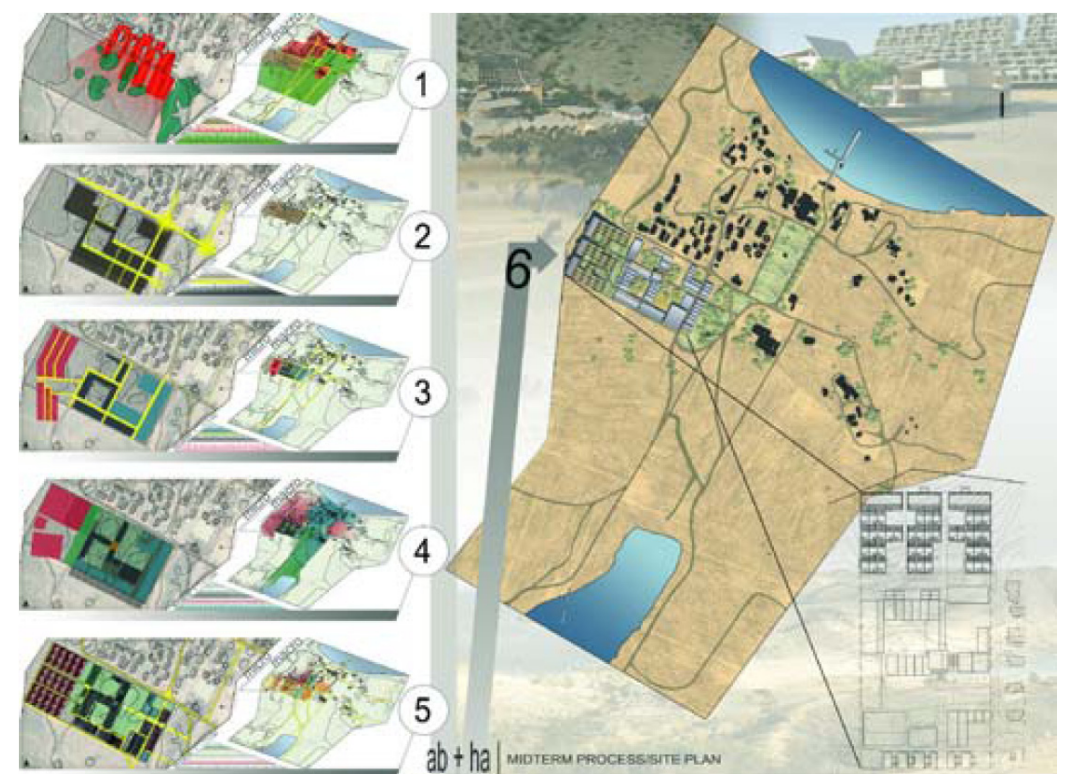

Figure 6: Mixed-use, self-sufficient infrastructure Scenarios for the next decades (10-150 years) for Two-Harbors, USC-Students: Harout Akopian, Alexander Babich.

The onsite and building integrated renewable powered infrastructure must integrate distributed energy resource (DER) systems with onsite small-scale power generation technologies (typically in the range of $3 \mathrm{~kW}$ to $10,000 \mathrm{~kW}$ ) including the options of small wind turbines, biomass power, cogeneration, micro turbines, fuel cells, electrolyzers, photovoltaic and solar thermal systems, waste water treatment, and rainwater collection and reuse (Figs. 5 and 6).

\section{Project criteria for the off-grid mixed-used Catalina Conservancy Middle Ranch hybrid buildings}

At least one of the main facilities of the Catalina Island Conservancy, such as the middle ranch, needs to be redeveloped and extended towards zero-fossil-energy operated buildings with distributed renewable energy and water infrastructures (Fig. 7).

The ecological building project development criteria consist of:

- A new zero-fossil-energy operated infrastructure including sustainable transportation systems

- Renewable powered, adaptable and flexible housings for staff, scientists and visitors of all ages

- Modular, adaptable, flexible science and testing labs

- Plug-and-play educational facilities for all ages

- Communal dining hall and kitchen areas 


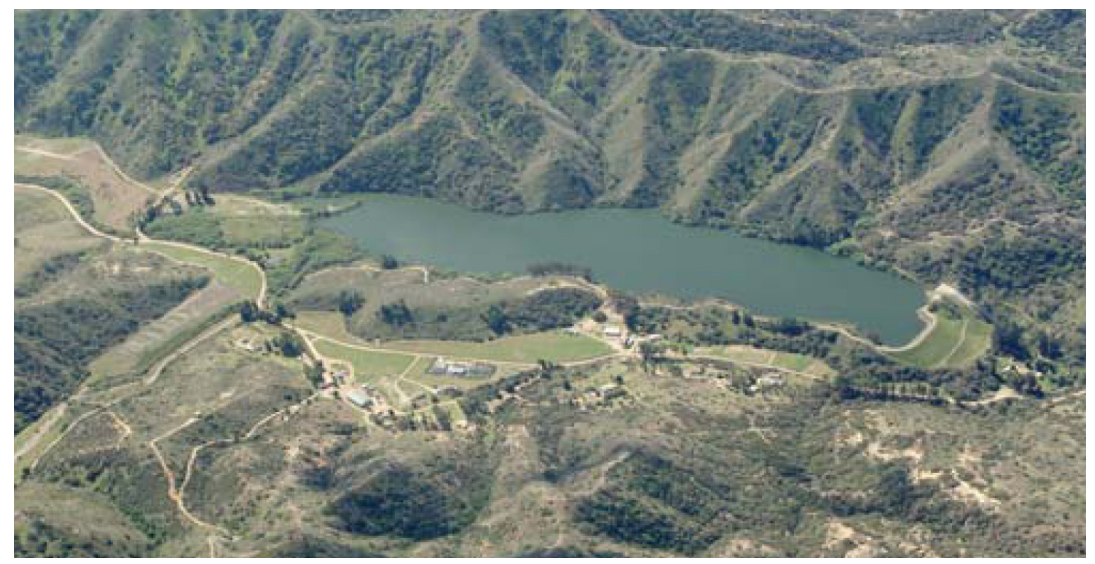

Figure 7: North-bird-view of the existing low-density Middle Ranch Facilities and Middle Canyon Water Reservoir, Image: Thomas Spiegelhalter.

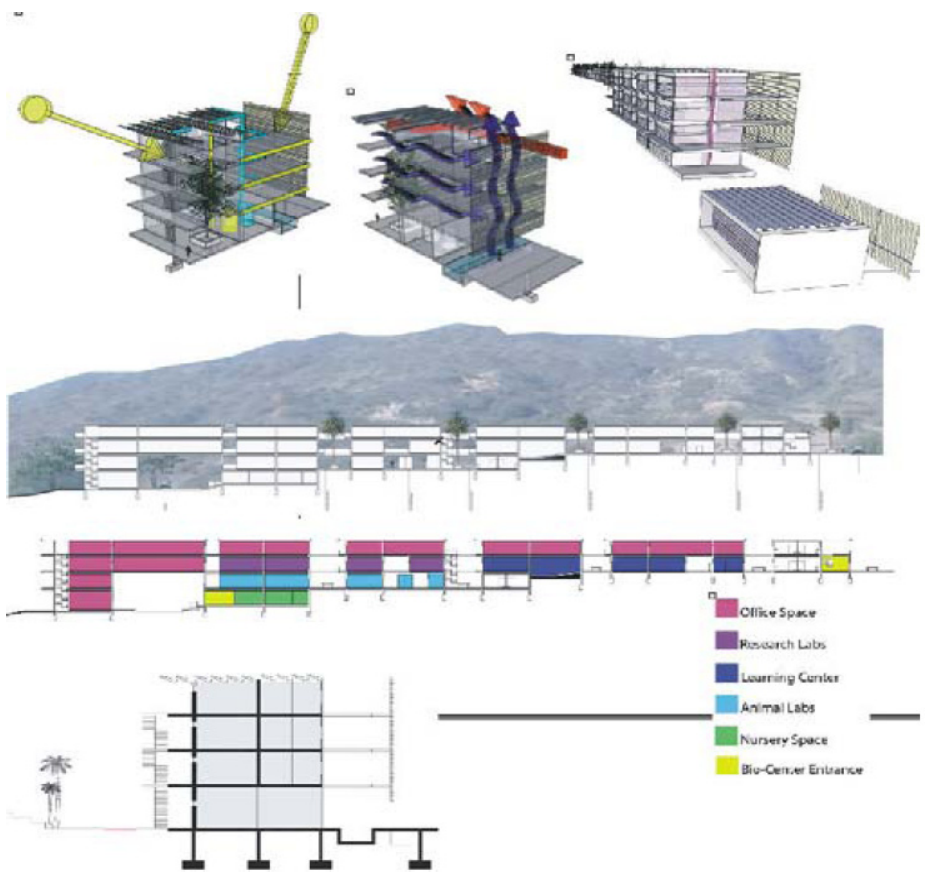

Figure 8: $\quad$ Mixed-use, self-sufficient, renewable highly densified, multistory live work clusters with building integrated solar shading, gaining, and daylight redirect-ting systems for the Middle Ranch, Design Students: Zoran Pevec, Matthew Goff. 
- Native plant gardens and adaptable nurseries

- Exhibit and demonstration areas

- Program and business offices

The design feasibility study explored new off-grid building typologies based on Catalina's typical natural resources and forces. The environmental building design had to be modular, affordable in its construction, maintenance, operation and life cycle. The landscape and building sites are analyzed on low versus high building footprint spatial temporal scales. Analysis precipitates different climate zones, building processes, circulation and form, for a site-specific type sustainable, highly densified modular and adaptable architecture (Fig. 8).

\section{Conclusions and future work}

As a result of the infrastructure assessment and efficiency, retrofit implementation strategy development, and the climate sensitive design research and feasibility study for Two Harbors and the Middle Ranch on Catalina Island, there are no generalized, single building design typology was identified that would be appropriate for the entire Island.

Buildings and infrastructure have to be developed based on the different microclimate zones and contextual site specialties of the changing occupancy through the seasonal peak times on Catalina. A reliable integrated resource master plan with a diversified renewable energy portfolio would help to make smart infrastructure and new building choices and ensure an economically, environmentally self-sufficient Island's infrastructure by 2020 (Fig. 9).

Furthermore, using contextual location metrics, the Island weather stations feedback data, and forecasted occupancy changes within the building infrastructure and the landscape requires the integration of future modular, adaptable and flexible structures, which allows easy reconfiguring, affordable maintenance, and operation of the different life cycles of the buildings and infrastructure systems.

Landscapes and solar passive design plays a major role for their operative and performative capacities in to safeguarding material, energy and water resources through the ecological alignment for new designed buildings and infrastructures on the island. Ecologically driven building orientation, using degree-days and degree-hours methods are necessary for the R-and U-Value enclosure simulations, to characterize the predicted climatic impact on the thermal behavior of the buildings.

For a better understanding of user demand and environmental long-term impact and demand, and the response potentials of buildings and infrastructures the Island needs to integrate annual post-occupancy monitoring systems and publicly accessible data sources for Sustainability awareness. The island also needs to establish diverse "lessons learned" manuals that will serve as guidelines for further projects on Catalina Island.

It is clear that Catalina Island does not have the economic or natural resources to sustain its current fossil-fuel infrastructure system into the future. 


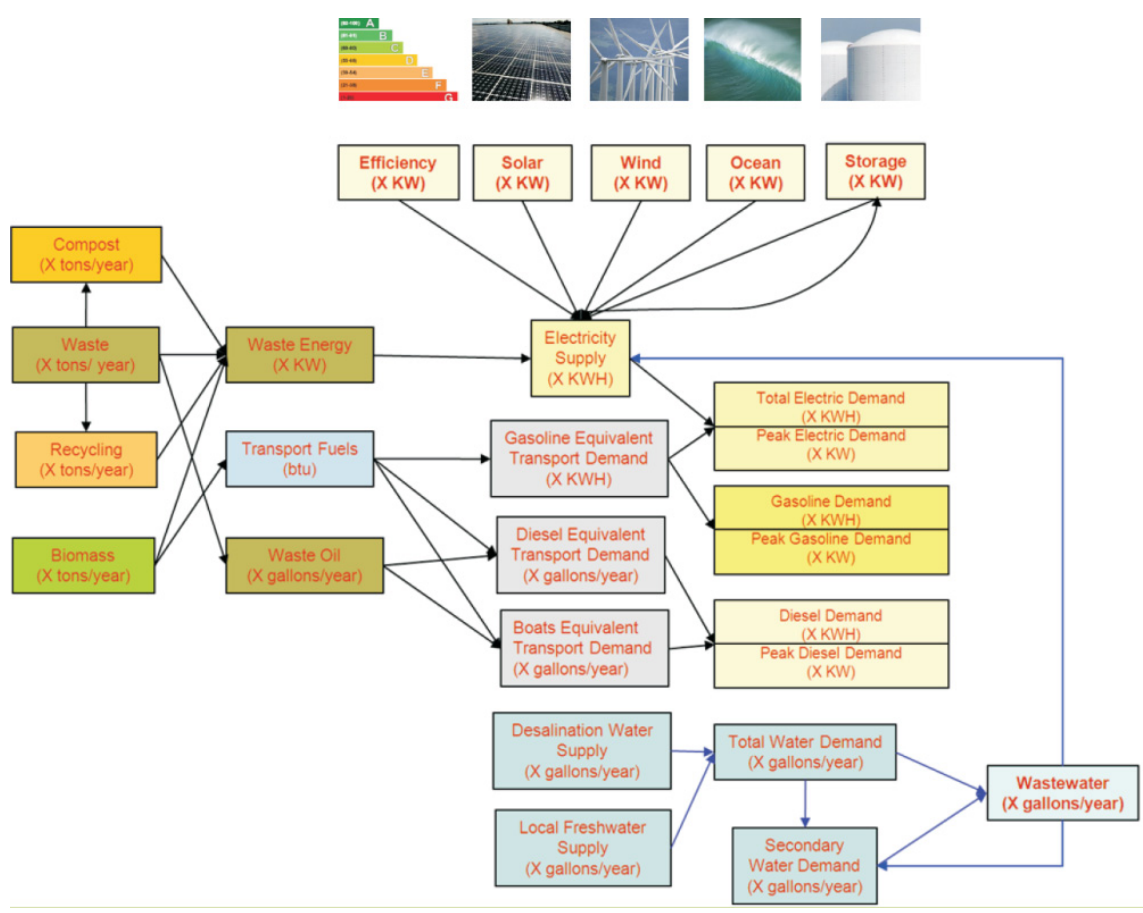

Figure 9: Thomas Spiegelhalter, Mark Bernstein: Future Renewable Infrastructure Energy Use Flow Diagram for Catalina Island, Catalina Island Sustainability Action Group Report, Nov. 10, 2008.

A viable future will only be possible by investing in a self-sufficient infrastructure system now, by retrofitting existing buildings with energy efficient appliances, materials, systems, and applying sustainability and annual energy performance auditing criteria to all new construction [2].

\section{Acknowledgements}

Thanks to Prof. Dr. Anthony Michaels, Former Director of the USC Wrigley Institute and Dr. Ann Muscat, President of the Catalina Island Conservancy for the generous financial support for travelling and lodging of 29 USC design research students on Catalina Island for two full weekends in 2007-2008

\section{Interviews}

Mel Dinkel, Chief Financial Officer, Catalina Island Conservancy.

Ann Muscat, President, Catalina Island Conservancy.

Prof. Dr. A. Michaels, Former Director of the USC Wrigley Environmental Institute.

Eric Berkheimer, Catalina Island Company, Avalon, California. 
304 Ecosystems and Sustainable Development VII

\section{References}

[1] Catalina Integrated Resource Plan, Edison, DSM Planning \& Integration, Nov. 13, 2008

[2] Thomas Spiegelhalter, "Develop a Baseline Building Energy Use Assessment and Building Energy Improvement Scenarios for Avalon on Catalina Island", Catalina island Sustainability Action Group Research Report, Nov. 10, 2008

[3] California Public Utilities Commission, Decision 02-04-016, April 4, 2002

[4] Wackernagel, M., W. Rees. 1996. Our Ecological Footprint: Reducing Human Impact on the Earth. Gabriola Island, BC: New Society Publishers. ISBN 0-86571-312-X.

[5] Apel, Richard W, "Avalon Community Profile." Report prepared for City of Avalon and Santa Catalina Island Company. March 2003. 